\title{
Investigation of Shallow Sedimentary Structure of the Anchorage Basin, Alaska, Using Simulated Annealing Inversion of Site Response
}

Article in Bulletin of the Seismological Society of America · February 2009

Impact Factor: $2.32 \cdot$ DOI: $10.1785 / 0120070250$

CITATIONS

2

4 authors, including:

Utpal Dutta

University of Alaska Anchorage

34 PUBLICATIONS 264 CITATIONS

SEE PROFILE
READS

25

Mrinal K. Sen

University of Texas at Austin

150 PUBLICATIONS 745 CITATIONS

SEE PROFILE 


\title{
Investigation of Shallow Sedimentary Structure of the Anchorage Basin, Alaska, Using Simulated Annealing Inversion of Site Response
}

\author{
by U. Dutta, M. K. Sen, N. Biswas, and Z. Yang
}

\begin{abstract}
This study deals with shallow sedimentary structure of the Anchorage basin in Alaska. For this purpose, inversion of site response [SR $(f)]$ data in the frequency range $0.5-11.0 \mathrm{~Hz}$ from various sites of the basin has been performed using the simulated annealing method to compute subsurface layer thickness, shear-wave velocity $(\beta)$, density, and shear-wave quality factor. The one-dimensional (1D) models for the aforementioned parameters were obtained with preset bounds on the basis of available geological information such that the $L-2$ norm error between the observed and computed site response attained a global minimum. Next, the spatial distribution of the important parameter $\beta$ was obtained by interpolating values yielded by the 1D models. The results indicate the presence of three distinct velocity zones as the source of spatial variation of $\mathrm{SR}(f)$ in the Anchorage basin. In the uppermost part of the basin, the $\beta$ values of fine-grain Quaternary sediments mainly lie in the range of $180-500 \mathrm{~m} / \mathrm{sec}$ with thickness varying from 15 to $50 \mathrm{~m}$. This formation overlies relatively thick (80-200 m) coarse-grain Quaternary sediments with $\beta$ values in the range of $600-900 \mathrm{~m} / \mathrm{sec}$. These two Quaternary units are, in turn, overlain on Tertiary sediments with $\beta>1000 \mathrm{~m} / \mathrm{sec}$ located at depths of 100 and $250 \mathrm{~m}$, respectively, in the central and western side along the Knik Arm parts of the basin. The important implication of the result is that the sources of spatial variation of $\operatorname{SR}(f)$ in the Anchorage basin for the frequency band $0.5-11 \mathrm{~Hz}$, besides in the uppermost $30 \mathrm{~m}$, are found to be deeper than this depth. Thus, use of commonly considered geological formations in the depth intervals from 0 to $30 \mathrm{~m}$ for the ground-motion interpretation will likely yield erroneous results in the Anchorage basin.
\end{abstract}

\section{Introduction}

Anchorage is the largest population center of the state of Alaska and is located in a highly active north Pacific seismic zone. According to national seismic hazard maps of the U.S. Geological Survey (Wesson et al., 1999), the seismic hazard level of Anchorage is around $0.4 \mathrm{~g}$ with a $10 \%$ probability of exceedence in 50 years. The major part of Anchorage lies on a sedimentary basin, which overlies a metamorphic terrane of the Chugach Mountains (CM) in the eastern part of the city. The basin formations dip towards the west and attain several kilometers of thickness. A stratigraphic test hole drilled (in the 1960s) in the western part of Anchorage to a depth of about $3.5 \mathrm{~km}$ failed to penetrate the bedrock. This indicates that the sedimentary deposits of the basin exceed few kilometers. These deposits range in age from the Upper Paleozoic through the Mesozoic (Yehle et al., 1986) and show widespread lithological variation from the eastern to western side of the city (Combellick, 1999). The sedimentary section immediately overlying the bedrocks is of the Tertiary age and consists of thick deposits of nonmarine sediments. These are overlain by several hundred meters of Quaternary coarse- grain sediments from at least five glacial advances from the surrounding mountain ranges. The retreating glaciers left behind complex deposits of heterogeneous sediments consisting of sandstone, siltstone, and claystone. The Bootlegger Cove Formation (BCF) is one of the important Quaternary units present in the uppermost few tens of meters in the Anchorage basin, particularly in the western and northeastern parts of the area; it consists of fine-grained silty sand and clay. The failure of this formation caused extensive damage in the area during the Prince William Sound earthquake $\left(M_{\mathrm{w}} 9.2\right)$ of 1964.

Following the catastrophic aftermath of the 1964 earthquake and the vigorous socioeconomic growth of Anchorage and its vicinity during the past four decades, the seismic hazards have become a major concern to the inhabitants of the area. In order to estimate the earthquake hazards in and around the Anchorage metropolitan area, a seismic microzonation project for Anchorage was initiated in early 1990s. Under this project, a number of seismological problems of earthquake engineering interest were investigated. These in- 
clude the estimation of $S$-wave site response (Dutta et al., 2001; Martirosyan et al., 2002), site classification from the shear-wave velocity structure of the uppermost $30 \mathrm{~m}$ of soil column using surface measurements of high-frequency Rayleigh-wave phase velocities (Nath et al., 1997; Dutta et al., 2000; Martirosyan et al., 2002; Badal et al., 2004), estimation of the shear-wave velocity structure of deeper sediments up to a depth of $1000 \mathrm{~m}$ from long period array measurements of microtremors (Dutta, Satoh, et al., 2007), frequency dependence of $S$-wave attenuation (Dutta et al., 2004), and source parameters of local earthquakes (Dutta et al., 2003).

As previously referred, the information on subsurface sedimentary structure for determination of the shear-wave motions in the Anchorage basin are primarily available from surface measurements. Results available from downhole measurements are very few, and most of them are limited to the uppermost few tens of meters. Martirosyan et al. (2003) related site response (SR) data in the frequency range 0.5$12 \mathrm{~Hz}$ from a few sites in the Anchorage basin with subsurface structure $(\sim 50 \mathrm{~m})$ by a one-dimensional (1D) forward modeling technique. Although dominant frequencies of SR values are well identified in this study, the observed SR variations as functions of frequency, $\operatorname{SR}(f)$, showed a poor correlation with the computed ones. These results revealed that, to explain the observed $\operatorname{SR}(f)$, more detailed information on the subsurface structure for shear-wave motions in the Anchorage basin is essential.

In the present study, the simulated annealing (SA) inversion technique (Sen and Stoffa, 1991, 1995) has been applied to the available $\operatorname{SR}(f)$ data (Dutta et al., 2001; Martirosyan et al., 2002) for the Anchorage basin to find optimal values of shear-wave velocity, thickness, density and shear-wave quality factor of the subsurface sediments $(0-600 \mathrm{~m})$ in such a way that an $L-2$ norm error between the observed and computed $\operatorname{SR}(f)$ attains a minimum. The prior bounds of the aforesaid parameters were set during the inversion process based on the available geological information.

\section{Data}

The site response in Anchorage was obtained from the analysis of weak-motion (WM) and strong-motion (SM) data collected at 40 sites in the study area as a part of the seismic microzonation project as mentioned earlier. The WM network consisted of 22 three-component IRIS-PASSCAL sensors (Mark Product L-28) and recorders (REF TEK) that were deployed in the free field and operated for about six months. The SM network consists of 20 stations that have been operational in the Anchorage area since 1995. Each station consists of a three-component Altus K2 (Kinemetrics Incorporated) accelerometer and has been installed on the concrete floor of a small one-storied building. Recently, the SM network has been densified in cooperation with the Advanced National Seismic System of the U.S. Geological Survey. Both the WM and SM stations have been distrib- uted within the basin covering different geological formations (Fig. 1). One station (An01) of the WM network and one station (K216) of SM network have been located on the metamorphic rocks of the Chugach Mountains in the eastern part of the area; these stations have been considered as reference stations for estimating the SR values.

The Fourier amplitude spectra $(0.5-11.0 \mathrm{~Hz})$ of the direct $S$-wave data from earthquakes recorded by both the WM and SM networks were used to compute $\operatorname{SR}(f)$ using standard spectral ratio (Martirosyan et al., 2002) and generalized inversion (GI) methods (Dutta et al., 2001). SR( $f$ )s were computed assuming that the reference stations (An01 for WM sites and K216 for SM sites) have unit site response in the aforementioned frequency range. The $\mathrm{SR}(f)$ results of standard spectral ratio (SSR) and GI agree well with each other for both the SM and WM sites. In the present study, we used these $\operatorname{SR}(f)$ data for inversion analysis.

\section{Methodology}

The frequency dependence of site response is primarily influenced by the shear-wave impedance contrast, layer thickness, and quality factor (Anderson et al., 1996; Bard and Riepl-Thomas, 2000). Accordingly, let $h_{i}, \beta_{i}, \rho_{i}$, and $Q_{i}$, respectively, indicate the thickness, shear-wave velocity, density, and shear-wave quality factor of the $i$ th layer of the subsurface. Therefore, the frequency-dependent SR can be expressed as

$$
\operatorname{SR}(f)=f_{1}\left(h_{1}, \beta_{1}, \rho_{1}, Q_{1}, \ldots \ldots \ldots, h_{N}, \beta_{N}, \rho_{N}, Q_{N}\right),
$$

where $f_{1}$ is the forward modeling operator. If $\operatorname{SR}(f)_{o}$ and $\mathrm{SR}(f)_{c}$ represent the observed and computed SR, respectively, then our aim is to estimate the model parameters (m) constituting $h, \beta, \rho$, and $Q$ of individual layers in such a way that the objective or error function,

$$
E(\mathbf{m})=\left\|\mathbf{S R}(f)_{o}-\mathbf{S R}(f)_{c}\right\|,
$$

attains a minimum. The symbol $\|\ldots\|$ in equation (2) represents a suitable chosen norm. We use here the $L 2$ norm such that

$$
E(\mathbf{m})=\left[\mathbf{S R}(f)_{o}-\mathbf{S R}(f)_{c}\right]^{T} \mathbf{C}_{S}^{-1}\left[\mathbf{S R}(f)_{o}-\mathbf{S R}(f)_{c}\right],
$$

where the superscript $T$ represents the matrix transpose and $\mathbf{C}_{s}$ is the data covariance matrix of SR. To search for the best possible values of the aforesaid model parameters, we used a simulated annealing method as described in the next section.

\section{Simulated Annealing}

SA mimics a liquid's recrystallization process of annealing in a heat bath. In an annealing process, a liquid that is initially in a disorderly state at high temperature $T$ is allowed to slowly cool in a thermodynamically equilibrium condi- 


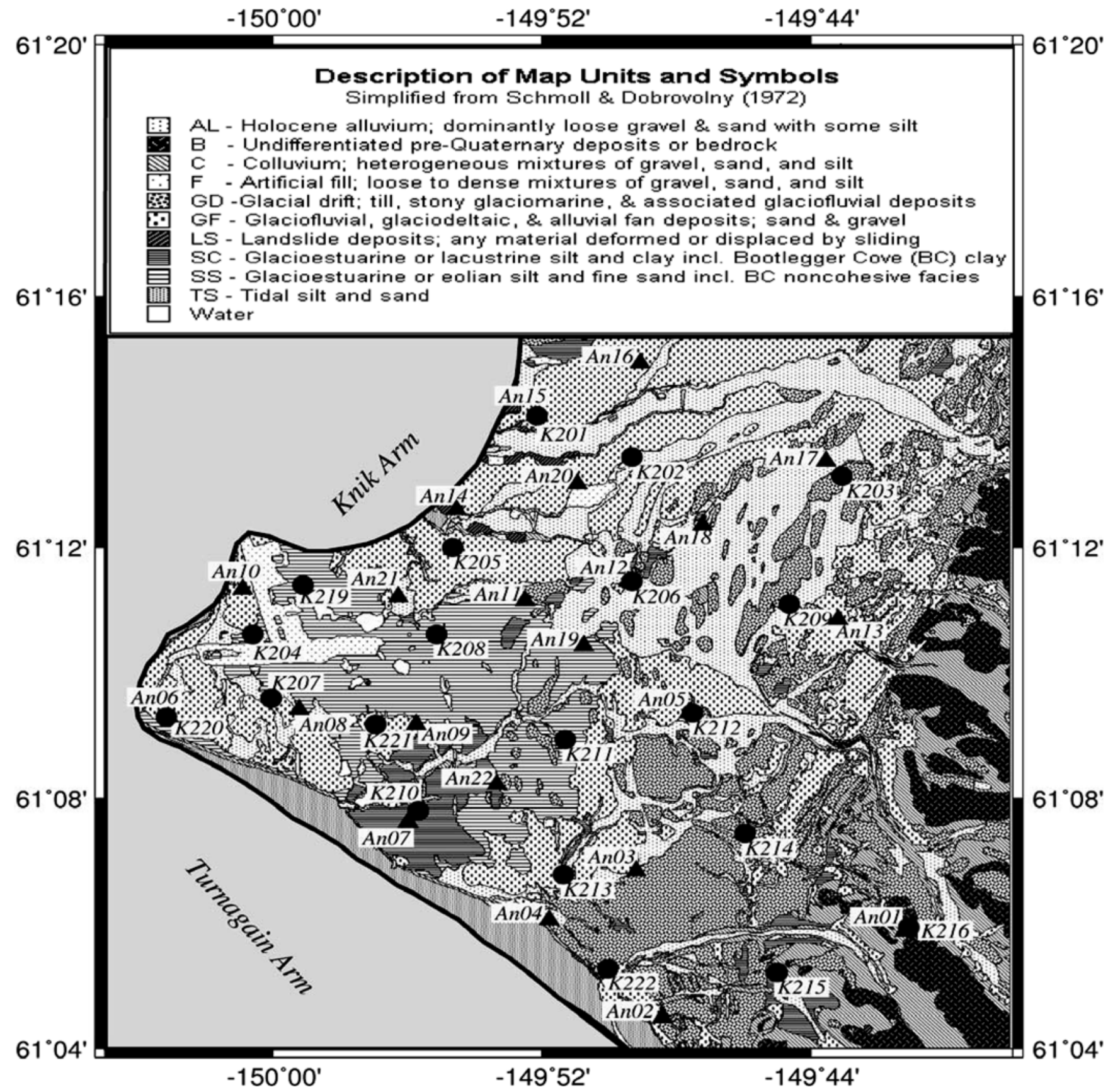

Figure 1. The weak (triangles) and strong (circles) motion station sites are plotted over the background of the geological map (Combellick, 1999) of the area. The site name of each station is also marked in the plot. The description of map units and symbols is simplified from Schmoll and Dobrovolny (1972).

tion. As cooling progresses, the system gradually attains an orderly state and then reaches a ground state. Metropolis et al. (1953) introduced the SA method by simulating evolution of a solid in a heat bath. The scheme is based upon the idea that an initial state of a thermodynamic system defined by energy, $E$, and temperature, $T$, is perturbed and the change of energy ( $\Delta E$ ) is computed. If $\Delta E$ is negative, the new configuration is accepted. If $\Delta E$ is positive, the new configuration can still be accepted but with a probability given by the Boltzmann factor $\exp (-\Delta E / T)$. This process is then repeated a num- ber of times to give good sampling statistics for the current temperature $T$. In the next step, the temperature is lowered and the entire process is repeated until a frozen state is achieved. Kirkpatrick et al. (1983) first introduced SA as a tool for the nonlinear geophysical inversion. Sen and Stoffa (1991) demonstrated the applicability of SA to seismic waveform inversion.

The inversion with the SA technique begins with an initial model $\mathbf{m}_{0}$. The energy of the system is analogous to the associated least-squares error $E\left(\mathbf{m}_{0}\right)$ between the observed 
and computed data as indicated in equation (2); the ground state is analogous to the global minimum of the least-squares error $E$. The temperature $T$ is analogous to a free parameter that controls the entire search process (Sen and Stoffa, 1995). Typically, $T$ is set at a very high value $(0.01)$ at the initial stage of iteration and is gradually lowered as the inversion progresses until it reaches around $10^{-9}$. During the process of iteration, the algorithm randomly draws a new model from the uniform distribution within a predefined limit of each model parameter. A variant of SA, called Very Fast Simulated Annealing (VFSA), is used here to draw a new model from a Cauchy-like distribution. This is achieved in the following way:

Assume that a model parameter $m_{i}$ at iteration $k$ is represented by $m_{i}^{k}$ such that

$$
m_{i}^{\min } \leq m_{i}^{k} \leq m_{i}^{\max },
$$

where $m_{i}^{\min }$ and $m_{i}^{\max }$ are the minimum and maximum values, respectively, of the model parameter $m_{i}$ set prior to the inversion. The aforementioned model parameter value is perturbed at the $(k+1)$ th iteration by using the following relation:

$$
\begin{gathered}
m_{i}^{k+1}=m_{i}^{k}+y_{i}\left(m_{i}^{\max }-m_{i}^{\min }\right), \quad \text { where } \quad-1 \leq y_{i} \leq 1 \\
\text { and } m_{i}^{\min } \leq m_{i}^{k+1} \leq m_{i}^{\max }
\end{gathered}
$$

$y_{i}$ is a random number generated following the Ingber distribution (Ingber, 1989) as follows:

$$
y_{i}=\operatorname{sgn}\left(u_{i}-\frac{1}{2}\right) T_{i}\left[\left(1+\frac{1}{T_{i}}\right)^{\left(2 u_{i}-1\right)}-1\right] \text {. }
$$

The random number $u_{i}$ is drawn from the uniform distribution of $U(0,1)$. The associated energy for the new model, $E\left(\mathbf{m}_{k+1}\right)$, is computed and compared with $E\left(\mathbf{m}_{k}\right)$. If $E\left(\mathbf{m}_{k+1}\right)<E\left(\mathbf{m}_{k}\right)$, then $\mathbf{m}_{k+1}$ is accepted unconditionally and replaces $\mathbf{m}_{k}$. However, if $E\left(\mathbf{m}_{k+1}\right)>E\left(\mathbf{m}_{k}\right)$, then $\mathbf{m}_{k+1}$ is accepted with a probability of $\exp \left(-\left[E\left(\mathbf{m}_{k+1}\right)-\right.\right.$ $\left.\left.E\left(\mathbf{m}_{k}\right)\right] / T\right)$. The rule of accepting the new model with a probability makes it possible for SA to jump out of the local minima. Such a generation-acceptance process is repeated several times at a particular constant temperature, $T$, and then $T$ is lowered according to a predefined cooling schedule and the process is repeated again. With fast cooling, the algorithm will be trapped in a local minimum; while slow cooling takes a long time, it will reach the global minimum. Hence, there is a trade-off between the accuracy and the computational costs. The algorithm is stopped when the error does not change after a sufficient number of trials. The VFSA speeds up the annealing process with minimum sacrifices of the solutions (Ingber, 1989); the method has been used by Sen and Stoffa (1996) for a number of geophysical applications.

\section{Uncertainty Estimation}

We allow the algorithm to perform several thousands of iterations (5000); thus, thousands of models were generated and the error $[E(\mathbf{m})]$ was calculated for each model. Therefore, the problem cannot have a unique solution; hence there is no real meaning of the best-fit model. Instead, we use all of the models to construct an approximate marginal posterior probability density (PPD) function using the Bayesian statistics and use several statistical measures, for example, variance and correlation (Sen and Stoffa, 1996) to represent the solution. While the variance gives the measure of the spread about the mean and thus provides the variability of each individual parameter, the correlation of one parameter with all other parameters reflects the ambiguities of interpretation. Following Tarantola (1987), the PPD $\left[\sigma\left(\mathbf{m} \mid \mathbf{d}_{\text {obs }}\right)\right]$ can be defined according to Bayes' theorem as

$$
\sigma\left(\mathbf{m} \mid \mathbf{d}_{\mathrm{obs}}\right) \propto l\left(\mathbf{d}_{\mathrm{obs}} \mid \mathbf{m}\right) p(\mathbf{m})
$$

where $\mathbf{m}$ is the vector containing a set of parameters, $\mathbf{d}_{\mathrm{obs}}$ is the data vector, $l\left(\mathbf{d}_{\mathrm{obs}} \mid \mathbf{m}\right)$ is the likelihood function expressing the conditional probability for the set of observation $\left(\mathbf{d}_{\text {obs }}\right)$ given set of parameter values $\mathbf{m}$, and $p(\mathbf{m})$ is the prior probability for $\mathbf{m}$ given to constrain the possible values of $\mathbf{m}$ independent of $\mathbf{d}_{\text {obs }}$. The likelihood function is proportional to $\exp [-E(\mathbf{m})]$, where $E$ is the error function as defined in equation 2 .

Thus, if the PPD is known, then the parameter mean or covariance can be obtained through the multidimensional integrals of the form

$$
\mathbf{I}=\int f(\mathbf{m}) \sigma\left(\mathbf{m} \mid \mathbf{d}_{\text {obs }}\right) d \mathbf{m},
$$

where $f(m)=\langle m\rangle$ for the mean and $f(m)=(m-\langle m\rangle) \times$ $(m-\langle m\rangle)^{T}$ for the parameter covariance matrix. We will use the variance and the correlation plots as the measurements to infer the quality of the interpreted results.

In contrast with the Monte Carlo or grid search algorithm that provides unbiased multidimensional PPD with more model evaluation than one can afford, the PPD estimated by VFSA is definitely biased towards its peak estimation due to the change of temperature control parameter during the selection process of model parameters. However, Sen and Stoffa (1996) argued that the VFSA algorithm could be repeated a number of times with different starting models to allow the sufficient sampling of the entire model space and thus minimize the biases in PPD. This will improve the estimates of the model covariance matrix and can also save several orders of magnitude in the number of model evaluation over either the Monte Carlo or grid search technique. 


\section{Forward Modeling and Model Parameterization}

We have used the program NRATTLE (Hartzell et al., 2003) to compute the linear transfer function (TF) of a damped, vertically propagating $S$ wave through a stack of horizontal layers based on the algorithm formulated by Kramer (1996). The SR at any site $\left[\operatorname{SR}(f)_{c}\right]$ has been computed by taking the ratio between $\mathrm{TF}$ of the respective sites $\left[T_{\text {comp }}(f)\right]$ and that at the reference site $\left[T_{\text {ref }}(f)\right]$, that is,

$$
\operatorname{SR}(f)_{c}=T_{\text {comp }}(f) / T_{\text {ref }}(f) .
$$

Because the observed $\operatorname{SR}(f)$ for the Anchorage basin were computed as previously mentioned with respect to the rock sites (An01 and K216) located on the metamorphic terrane of the Chugach Mountains in the eastern part of the basin, we used a 1D-layered Earth model of this site to compute $T_{\text {ref }}(f)$. Martirosyan et al. (2002) has shown that the rock sites of the Anchorage basin do not have unit site response above $7.0 \mathrm{~Hz}$, as these sites overlay weathered rocks due to constant freezing and thawing in the area. Recent borehole drilling data at the rock site indicate that a $4 \mathrm{~m}$ thick weathered rock overlays the hard rock. Therefore, a twolayered Earth model was used to compute $T_{\text {ref }}(f)$ using the forward modeling program (NRATTLE) in the frequency range $0.5-11.0 \mathrm{~Hz}$. This model consists of a $4.5 \mathrm{~m}$ thick layer that overlies a half-space with shear-wave velocity, density, and shear-wave $Q$ as $600 \mathrm{~m} / \mathrm{sec}, 2.2 \mathrm{gm} / \mathrm{cc}$, and 50 for the upper and $1800 \mathrm{~m} / \mathrm{sec}, 2.5 \mathrm{gm} / \mathrm{cc}$, and infinity, respectively, for the half-space. The computed $T_{\text {ref }}(f)$ is approximately unity in the frequency range $0.5-8.0 \mathrm{~Hz}$ and gradually increases to 1.5 at $11.0 \mathrm{~Hz}$, which is the expected site response of the rock sites in the Anchorage basin.

The inversion of $\operatorname{SR}(f)$ data has been performed to simultaneously estimate a 1D-layered Earth structure for three model parameters, namely $\beta, \rho$, and $Q$ (see equation 1 ). The optimal values for each parameter were searched within their individual ranges set a priori. Although the observed SR $(f)$ for a layered Earth structure is a function of both impedance contrast and $Q$, the variation of $\beta$ of the subsurface sediments influences the $\operatorname{SR}(f)$ much more than the others. However, in the inversion process, we include $\rho$ and $Q$ as model parameters and independently estimate their 1D variation with a depth under the imposed constraint on their probable values for the sedimentary basin. This seems to be more reasonable than to assume any depth dependent relation for them in the inversion process.

We assumed a 14-layered Earth model to represent the sedimentary section of the Anchorage basin that overlies the half-space as previously defined and computed $T_{\text {comp }}(f)$ for all of the sites. To represent the effect of near surface velocity variation on the observed SR, we have considered eight layers from available geological information to represent the uppermost $100 \mathrm{~m}$ of the sedimentary section. The maximum $\left(\beta_{\max }\right)$ and minimum $\left(\beta_{\min }\right)$ allowable velocities of these layers were assigned $\pm 60 \%$ of the average velocity obtained from the borehole data (Fig. 2), whereas the density and $Q$ were allowed to vary between 1.8 and $2.2 \mathrm{gm} / \mathrm{cc}$ and 1 and 50, respectively (Dowl Engineers, 1985; WoodwardClyde Consultants, 1987). The maximum target depth is selected to be $650 \mathrm{~m}$ in the frequency range of interest $(0.5-11.0 \mathrm{~Hz})$ following the observation of Hartzel et al. (2003) who found that SR does not appreciably change beyond this depth limit. We have used six layers with thicknesses increasing with depth to represent the sedimentary section between 100 and $600 \mathrm{~m}$ depth intervals. Because of the lack of any velocity data from deep boreholes $(>100 \mathrm{~m})$ in the Anchorage bowl, the $\beta_{\min }$ and $\beta_{\max }$ of these sediments were assumed to gradually increase with depths from 600 and $700 \mathrm{~m} / \mathrm{sec}$ to 1400 and $1800 \mathrm{~m} / \mathrm{sec}$, respectively. The range of $\rho$ and $Q$ variation were assumed to be between $2.2-2.4 \mathrm{gm} / \mathrm{cc}$ and $10-150$, respectively, values typical of sedimentary formations. This a priori information of the model parameters was set during the inversion analysis of the site response data for all of the sites considered in this study (Fig. 1).

\section{Results and Discussion}

Following the aforesaid scheme, we inverted the SR data in terms of $\beta, \rho, h$, and $Q$ for the sedimentary structure. The results are shown in Figures 3-7 for five representative sites located in site classes $C, C / D$, and $D$. These site classes were estimated by Martirosyan et al. (2002) based on the results of an average of $30 \mathrm{~m}$ shear-wave velocity data of the Anchorage basin (Dutta et al., 2000). Of the five sites, one site (K203) is located in the area of site class C on the eastern side of the basin. The result of inversion for this site is given in Figure 3. Similarly, the results of inversion for two sites (K213 and K211) are shown in Figures 4 and 5, respectively. These two sites are located in the area of site class C/D in the south central and central parts of the basin. The results of the other two sites (K220 and K201) are shown in Figures 6 and 7 , which are located in the area of site class D. Of these two sites, K220 lies onshore of Turnagain Arm and K201 lies in the onshore area of Knik Arm.

The results shown in Figures 3-7 represent the same quantities; for instance, in the upper panel of each figure the observed SR (solid lines) and those computed (dashed lines) for the mean model obtained from inversion are plotted as a function of frequency. In the lower panel, 1D variation of the mean values of three model parameters, namely the shear-wave velocity, density, and shear-wave $Q$ with depth are shown. The dashed and dotted lines in each plot indicate the maximum and minimum allowable values of individual model parameters assigned for each layer during the inversion; the shaded areas represent $\pm 1 \sigma$ variation of the respective mean values, where $\sigma$ is the standard deviation. It may be noted in Figures 3-7 that the observed SR values at each site are well explained by a 1D-layered Earth model obtained 


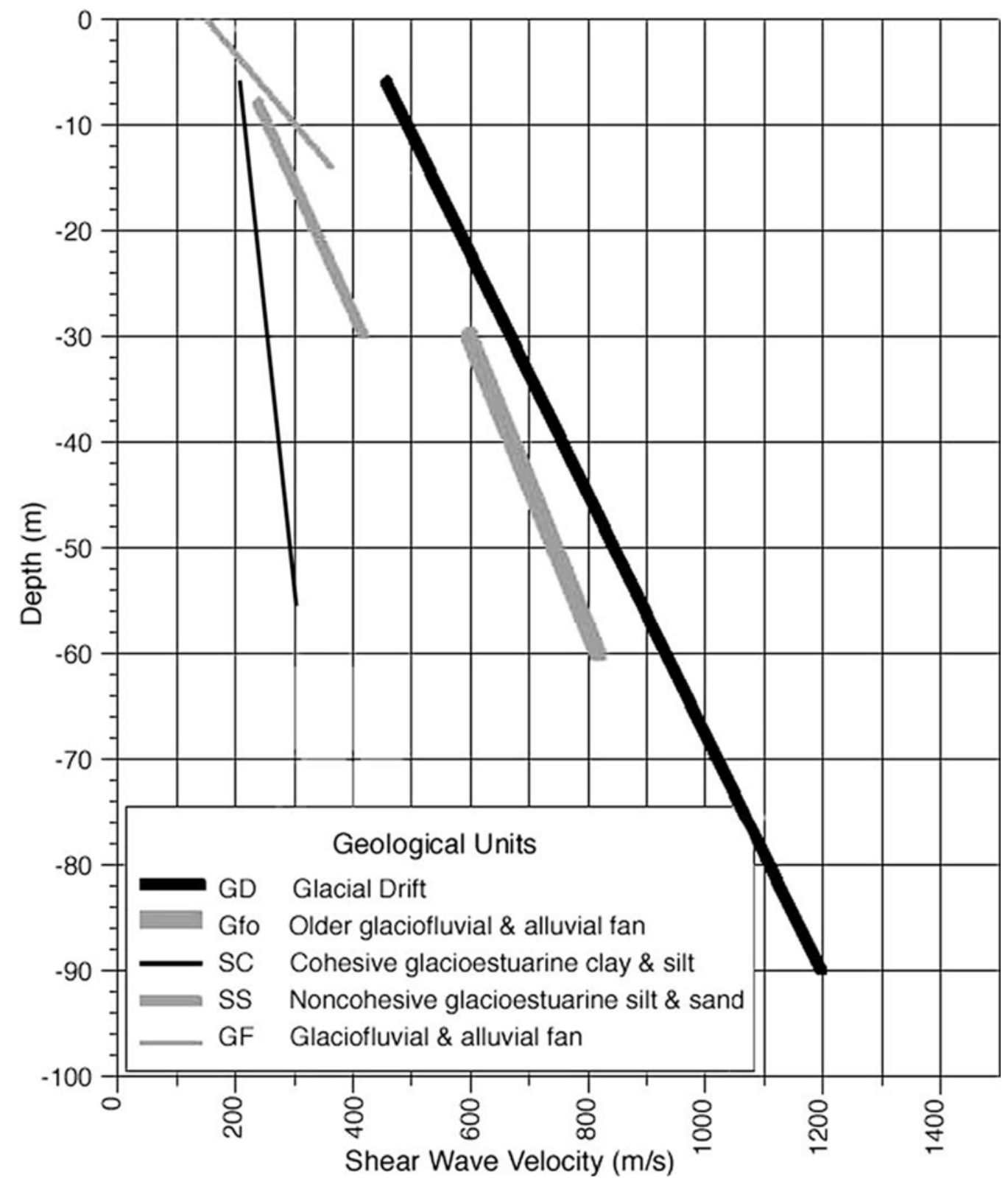

Figure 2. Depth dependence of the average shear-wave velocity for various geological formations in Anchorage, Alaska (Martirosyan et al., 2003).

from the inversion. This is also the case with all other sites (Fig. 1) in the Anchorage basin.

The model obtained from inversion for site K203 shows that the $\beta$ value gradually increases from $220 \mathrm{~m} / \mathrm{sec}$ at the surface to $500 \mathrm{~m} / \mathrm{sec}$ at a depth of $60 \mathrm{~m}$ (Fig. 3b). Below a $60 \mathrm{~m}$ depth, a low-velocity zone (LVZ) of approximately $35 \mathrm{~m}$ thick occurs with $\beta$ around $480 \mathrm{~m} / \mathrm{sec}$. Beneath the LVZ, $\beta$ gradually increases with depth up to the half-space at a depth of $420 \mathrm{~m}$. The density model shows a zone of reversal in the same depth interval as $\beta$-LVZ. Below this depth, the density gradually increases up to the top of the half-space (Fig. 3c). The $S$-wave $Q$ model (Fig. 3d) shows gradual increase from the surface to the top of the half-space.
The inversion results for the two sites, K213 and K211, in the south central and the central parts of the basin are shown in Figures 4 and 5, respectively. The $\beta$ structures of both of the sites show a gradual increase of $\beta$ from $250 \mathrm{~m} / \mathrm{sec}$ at the surface to around $1000 \mathrm{~m} / \mathrm{sec}$ at a depth of $70 \mathrm{~m}$ (Figs. 4b and 5b). Below this depth, the models yielded a LVZ with $\beta$ around $800-850 \mathrm{~m} / \mathrm{sec}$ and thicknesses of 110 and $200 \mathrm{~m}$. Below the LVZ, the $\beta$ increases with depth and attains a value of $1800 \mathrm{~m} / \mathrm{sec}$ at a depth of 420 and $450 \mathrm{~m}$, respectively, for sites K213 and K211. The variations of $\rho$ and $Q$ with depth at these two sites are nearly identical and show gradual increase with depth (Figs. 4c and 5c; Figs. 4d and 5d). 
(a)

Site: K203
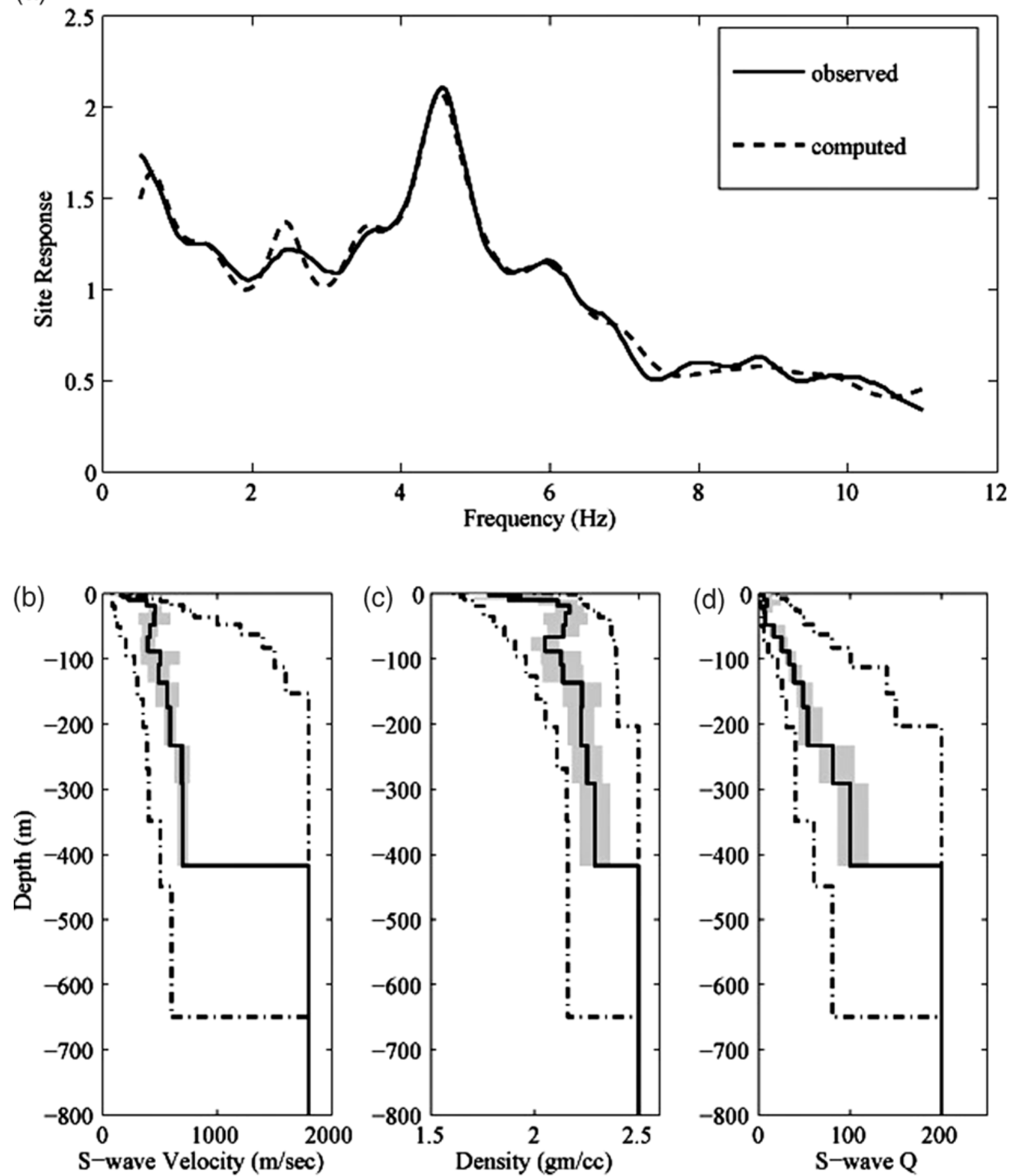

Figure 3. The results of inversion of site response data for site K203. (Top) (a) The observed site response and that computed for the mean model obtained from inversion are shown by the solid and dashed line, respectively. (Bottom) The figures show a 1D variation of the mean model (solid line) with depth obtained from the inversion of site response data for three model parameters: (b) shear-wave velocity, (c) density, and (d) shear-wave $Q$. The dashed and dotted lines in each plot indicate the upper and lower bounds of the search region for three parameters. The shaded areas in each plot indicate a $\pm 1 \sigma$ variation of respective parameter about their mean values, where $\sigma$ is the standard deviation.

The Figure 6 shows the 1D-layered Earth model for site K220, which is located on the western part of the basin. The model shows that the $\beta$ values increase from $180 \mathrm{~m} / \mathrm{sec}$ at the surface to $1000 \mathrm{~m} / \mathrm{sec}$ at a depth of $300 \mathrm{~m}$. This indicates that the $\beta$ of sediments from the uppermost few hundred meters are relatively lower (Fig. 6b) than the sediments belonging to the sites located on the central and south central parts of the basin where the sediments of $\beta \sim 1000 \mathrm{~m} / \mathrm{sec}$ have been found at relatively shallower depth $(\sim 70 \mathrm{~m})$. Moreover, the density values of the sediments for the upper- 
(a)

Site: K213
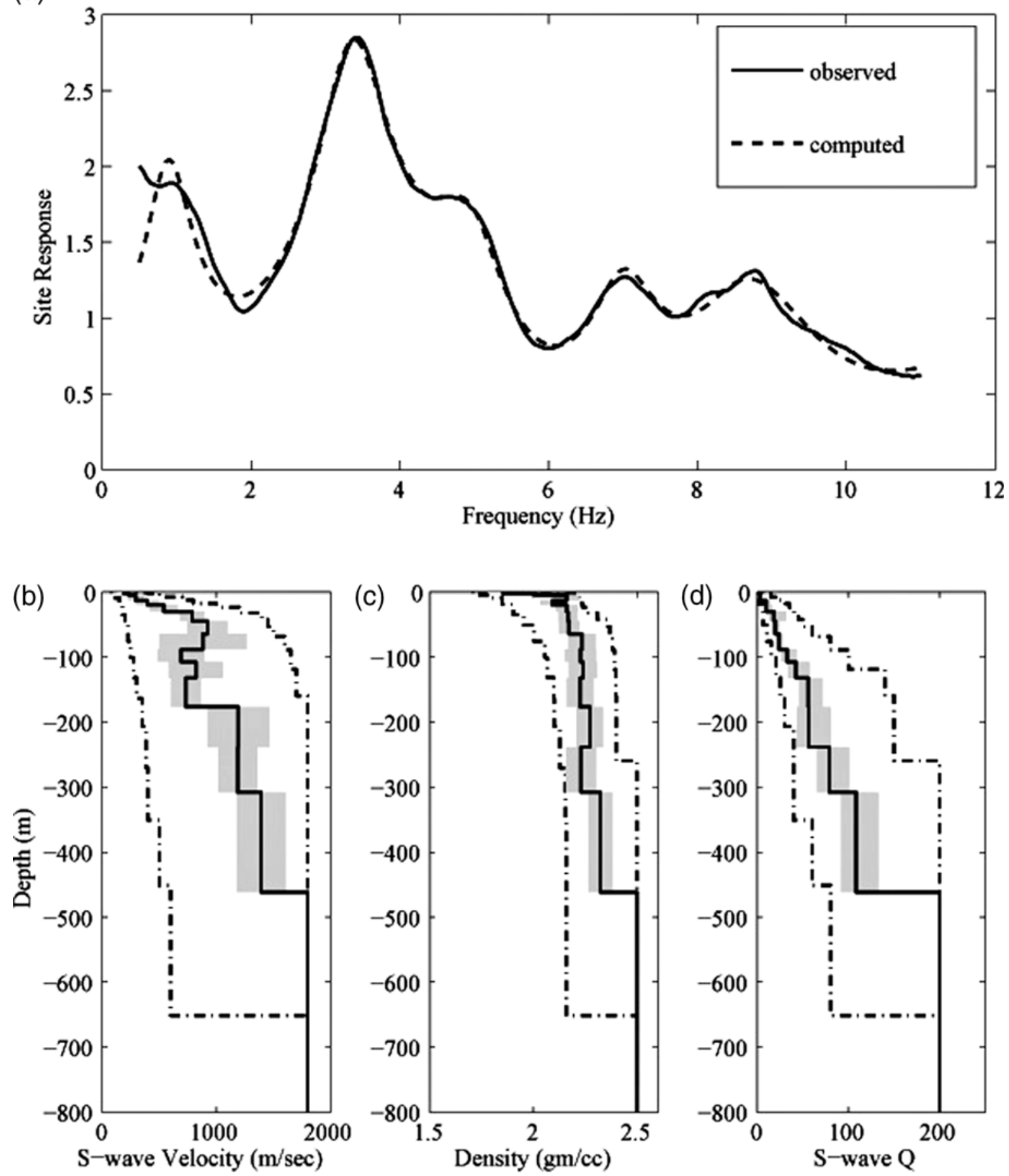

Figure 4. Same as in Figure 2 but for site K213.

most $50 \mathrm{~m}$ (Fig. 6c) have also been found to be lower compared to the sites located in site class $C / D$, but no significant changes are noticed in the $Q$ structure (Fig. 6d) yielded by the model.

The model obtained from inversion at the northeastern part of the basin (site K201) indicates that the $\beta$ structure of the sediments increases sharply from 600 to $1200 \mathrm{~m} / \mathrm{sec}$ between a 50 and $180 \mathrm{~m}$ depth interval (Fig. 7b) along with the increase of density from 2.1 to $2.4 \mathrm{gm} / \mathrm{cc}$ (Fig. 7c). This is in contrast to site $\mathrm{K} 220$, although both sites are located in the same site class D area. An LVZ of $120 \mathrm{~m}$ thick with $\beta \sim$ $1000 \mathrm{~m} / \mathrm{sec}$ was yielded by the model for this site at a depth of $180 \mathrm{~m}$. Below the LVZ, the $\beta$ values of the sediments gradually increase again with depth and reach to $1800 \mathrm{~m} / \mathrm{sec}$ at a depth of $450 \mathrm{~m}$.

We interpret that the fine-grain Quaternary sediments of the Anchorage basin, which include the BCF in the western parts and the glaciofluvial deposit in the northeastern and 
(a)

Site: K211
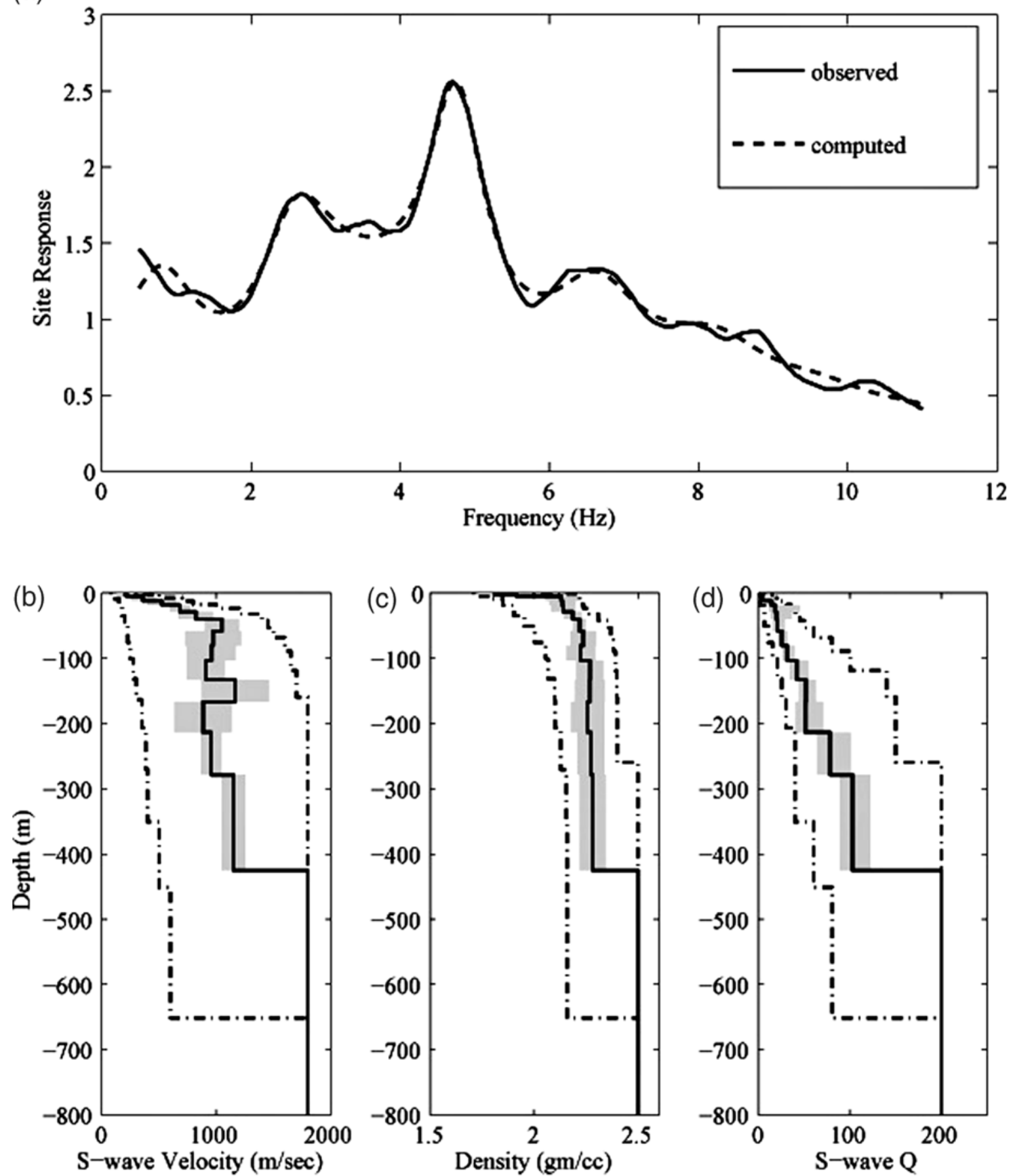

Figure 5. Same as in Figure 2 but for site K211.

some areas of the central parts of the basin (Combellick, 1999) have shear-wave velocity in the range of 180$500 \mathrm{~m} / \mathrm{sec}$. The thickness of the fine-grain Quaternary sediment is minimum $(\sim 15-20 \mathrm{~m})$ in the central part and maximum $(\sim 60 \mathrm{~m})$ in the western parts of the basin. Along the north-south direction of the basin, the thickness is approximately about $40 \mathrm{~m}$ in the south central part and increases to $60 \mathrm{~m}$ in the northeastern part of the basin. The fine- grain sediments that overlie the coarse-grain sediments mainly consist of the glacial till deposits by different glacial advances in the basin from the surrounding mountains in the geological past. The $\beta$ values of the coarse-grain sediments vary significantly across the basin as well as with depth from 600 to $900 \mathrm{~m} / \mathrm{sec}$. The coarse-grain sediments overlie on the Tertiary sediments with $\beta>1000 \mathrm{~m} / \mathrm{sec}$. The depth of the Tertiary sediments in the basin is around $250 \mathrm{~m}$ in the western parts of the basin along the Knik Arm and appears to be highly undulating in the central parts of the study area with 
(a)

Site: K220
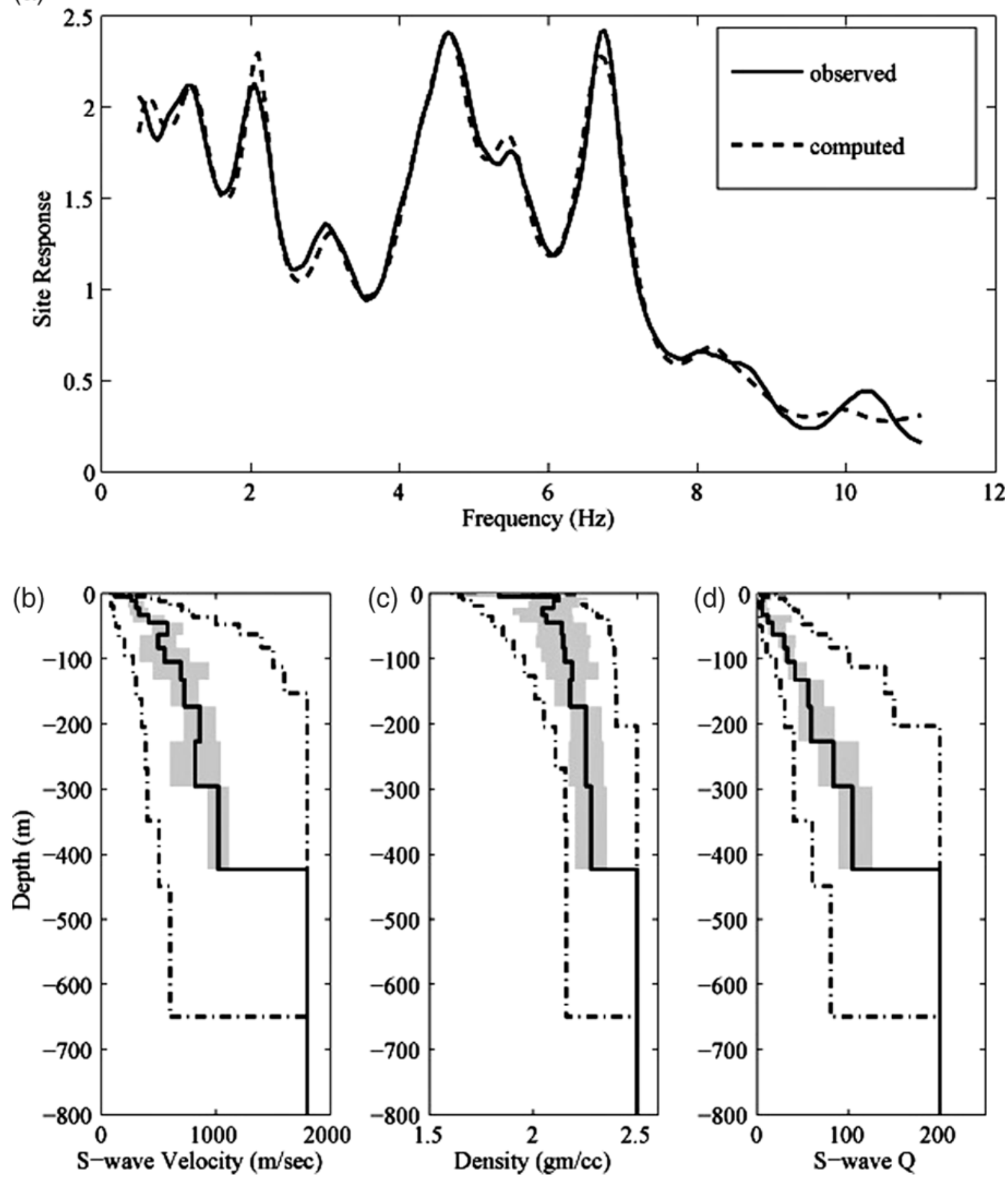

Figure 6. Same as in Figure 2 but for site K220.

depth varying from 150 to $300 \mathrm{~m}$. Over the eastern parts of the basin, the boundary between the coarse-grained Quaternary and the Tertiary sediments is difficult to assign. The borehole data (Combellick, 1999) indicate the depth to the top of the Tertiary sediments to be shallow ( 40-50 m) in this area, but the inversion results do not show the presence of high-velocity sediments at this depth. It appears that this may be due to the fact that the $\beta$ values of the Tertiary sedi- ments in this area are low (around $800 \mathrm{~m} / \mathrm{sec}$ ) compared to those in the deeper parts of the basin.

Spatial Variation of Shear-Wave Velocity in the Anchorage Basin

In order to illustrate the spatial variation of $\beta$ in the Anchorage basin, we have interpolated, using the Delaunay 
(a)

Site: K201

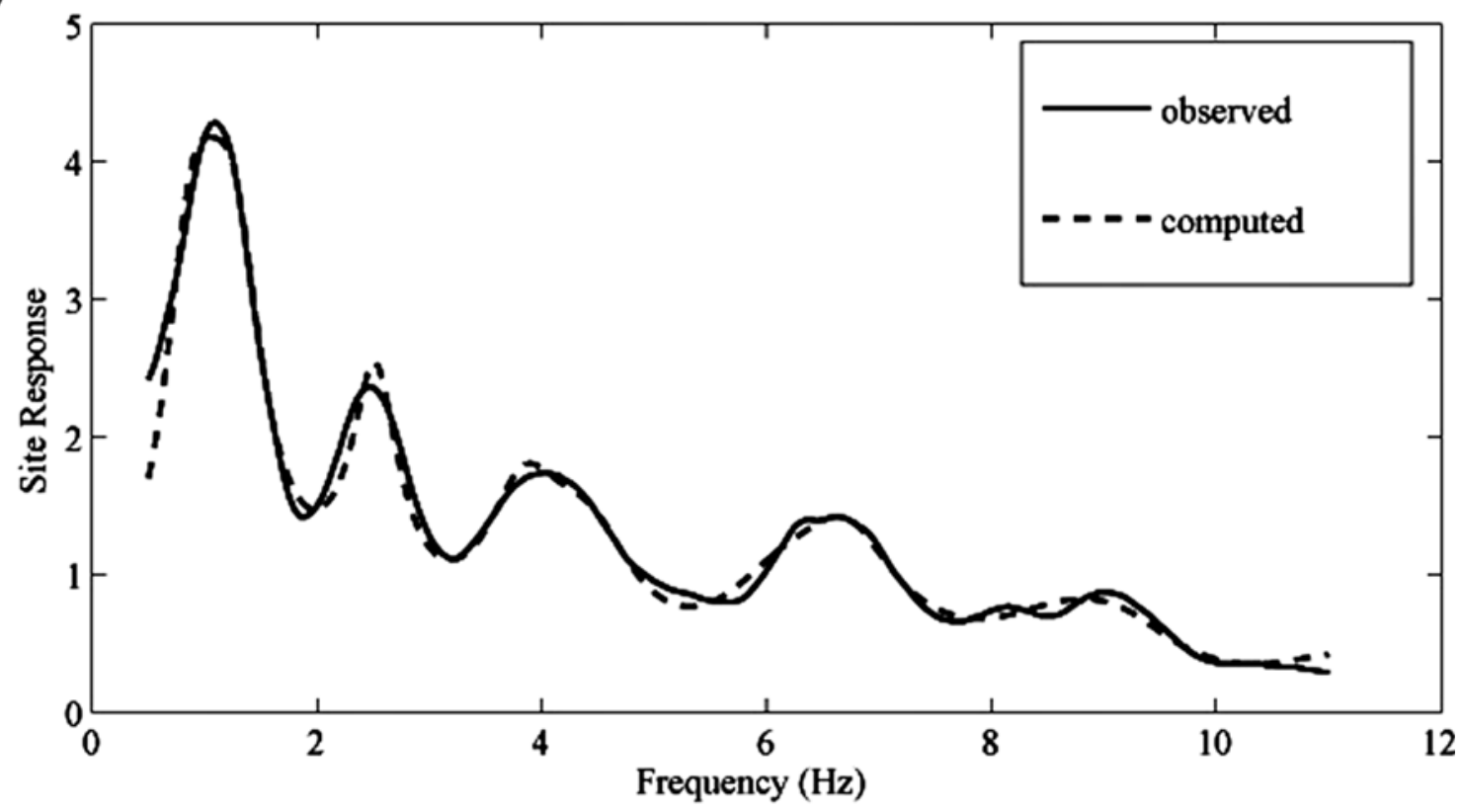

(b)

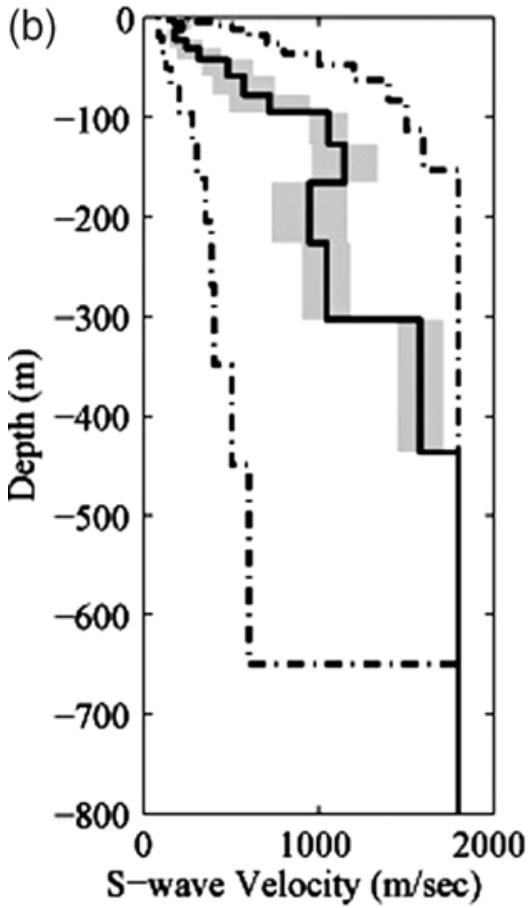

(c)

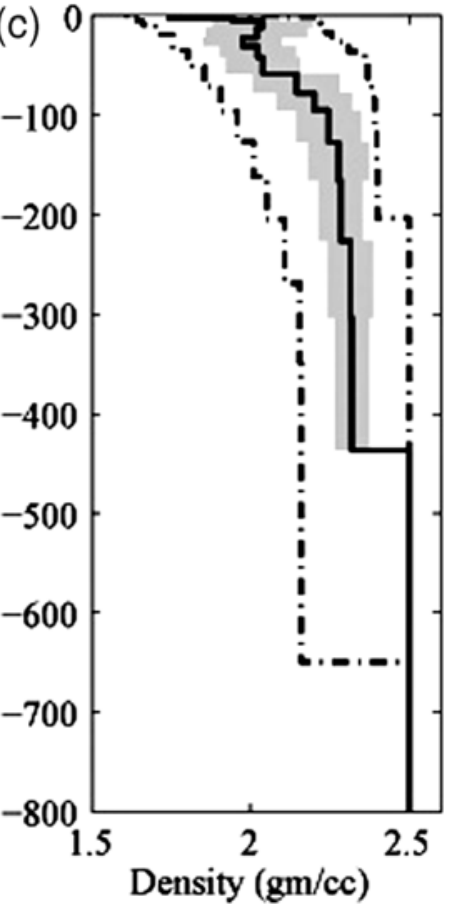

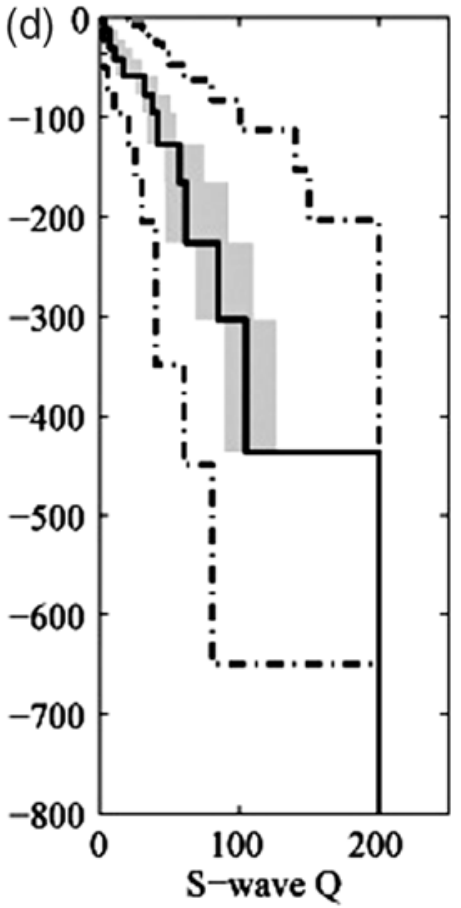

Figure 7. Same as in Figure 2 but for site K201.

triangulation method (Wessel and Smith, 1998), the 1D structure obtained at different sites (Fig. 1). The results of $\beta$ for different depths for the uppermost $300 \mathrm{~m}$ are shown in map view in Figure 8; below this depth, $\beta$ nominally varies.

At a $30 \mathrm{~m}$ depth, three areas in the western section of the basin show distribution of sediments with $\beta$ in the range of $200-400 \mathrm{~m} / \mathrm{sec}$. The available geological map of Anchorage (Updike and Ulery, 1986) shows that these areas are associated with the BCF, which suffered extensive ground failure during the 1964 Prince William Sound earthquake $\left(M_{\mathrm{w}} 9.2\right)$ as mentioned earlier. Moreover, of the three areas with low $\beta$, particularly in the central one, the available results from downhole measurement indicated the occurrence of BCF in the 15-45 m depth range (Dutta, Sen, et al., 2007). The central part of the basin revealed sediments (glacial till) with $600 \mathrm{~m} / \mathrm{sec}<\beta<800 \mathrm{~m} / \mathrm{sec}$. The southwestern section of the study area is an area of high $\beta(>1000 \mathrm{~m} / \mathrm{sec})$ with the highest value in between 1600 and $1800 \mathrm{~m} / \mathrm{sec}$. It coin- 


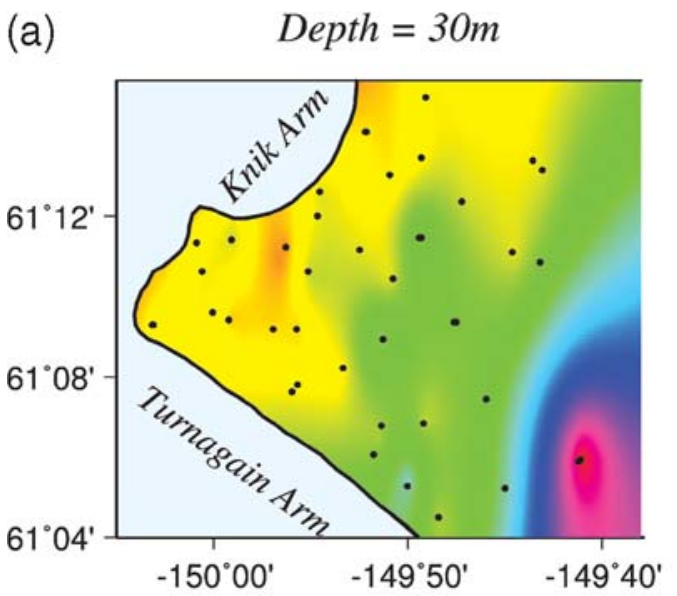

(b) Depth $=100 \mathrm{~m}$

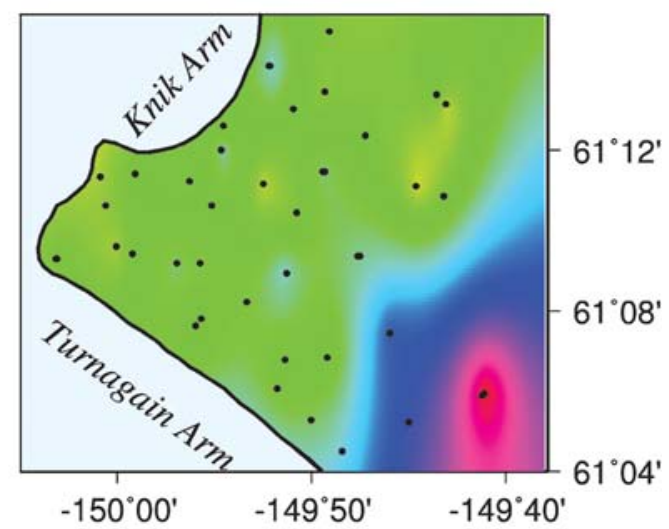

(d) Depth $=300 \mathrm{~m}$

(c)

Depth $=200 \mathrm{~m}$

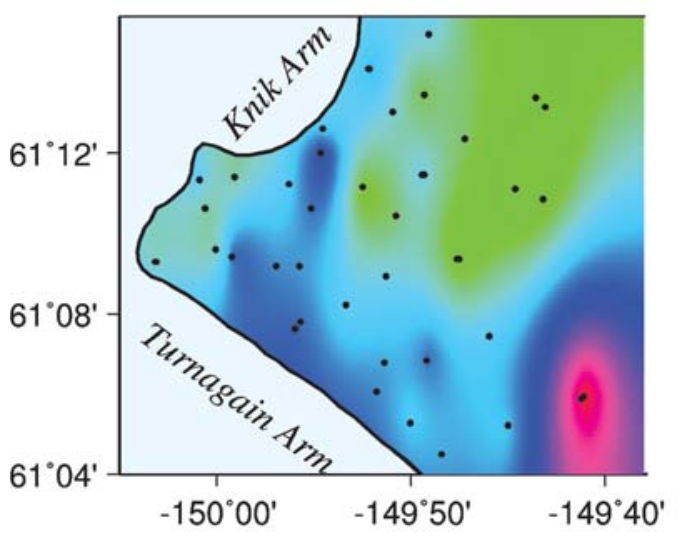

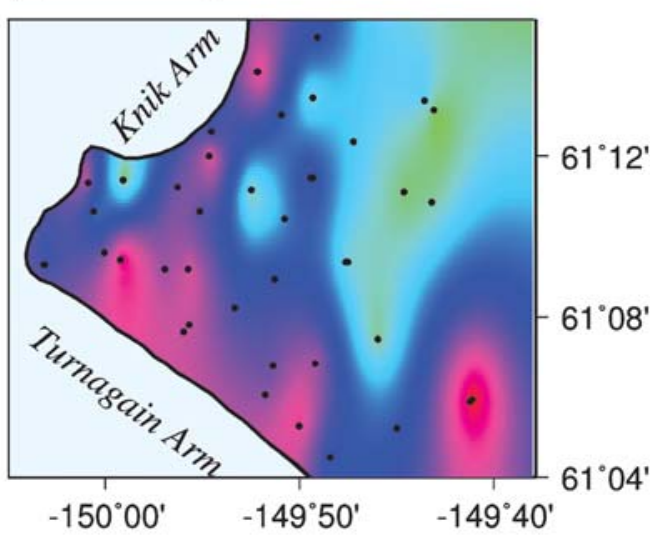

$-150^{\circ} 00^{\prime} \quad-149^{\circ} 50^{\prime} \quad-149^{\circ} 40^{\prime}$ $61^{\circ} 12^{\prime}$

$61^{\circ} 08^{\prime}$

$61^{\circ} 04^{\prime}$

Shear Wave Velocity $(\mathrm{m} / \mathrm{s})$

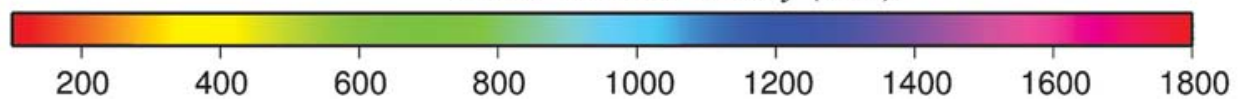

Figure 8. (a)-(d) The spatial variation of shear-wave velocity in the Anchorage basin obtained from the inversion of site response data at various depth levels as marked on the top of each plot. The dots indicate site locations. The horizontal bar at the bottom of the figure explains the color code of shear-wave velocity.

cides with the southern extension of the Chugach Mountains consisting of metamorphic rocks.

At a $100 \mathrm{~m}$ depth, with the exception of southeast section, the rest of the area comprises sediments of $600 \mathrm{~m} / \mathrm{sec}<\beta<900 \mathrm{~m} / \mathrm{sec}$. In the southeast section, the spatial characteristics of formations are similar to those obtained at a $30 \mathrm{~m}$ depth. However, the lateral extent of formations of $1000 \mathrm{~m} / \mathrm{sec}<\beta<1200 \mathrm{~m} / \mathrm{sec}$ increases compared to that of a $30 \mathrm{~m}$ depth. These formations, beside the southeast section, occupy most of the coastal area of the Turnagain Arm at a $200 \mathrm{~m}$ depth. In the western part of the basin, these formations extend to the coastal area of the Knik Arm. At a $300 \mathrm{~m}$ depth, the high-velocity formations of $1600<\beta<1800 \mathrm{~m} / \mathrm{sec}$ occur along the coastal area of the Turnagain Arm, and a strand of these formations extends to the coastal area of the Knik Arm through the western part of the basin. The westernmost and northwestern parts of the basin are characterized by sediments of $1000 \mathrm{~m} / \mathrm{sec}<$ $\beta<1200 \mathrm{~m} / \mathrm{sec}$. Most of the northeastern parts of the study area that has data coverage are occupied by sediments of $500 \mathrm{~m} / \mathrm{sec}<\beta<800 \mathrm{~m} / \mathrm{sec}$.

The spatial variations of $\beta$ from the present study show an overall agreement with those obtained by Dutta, Satoh, et al. (2007) from the inversion of phase velocity data using the microtremor survey at nine sites in the Anchorage basin. The results of both Dutta, Satoh, et al. (2007) and the current study indicate the presence of relatively low-velocity sediments $(200-400 \mathrm{~m} / \mathrm{sec})$ in the western and west central parts of the Anchorage basin at a shallow depth (30-60 m) compared to the high-velocity $(600-900 \mathrm{~m} / \mathrm{sec})$ sediments in the eastern parts of the area. The only noticeable difference in shear-wave velocity values from these two studies is observed along the foothills of the Chugach Mountains between a 60 and $220 \mathrm{~m}$ depth interval, where the current 
study indicates the presence of relatively low $\beta$ (600$800 \mathrm{~m} / \mathrm{sec}$ ) for the sediments in contrast to high value (1200-1300 m/sec) reported by Dutta, Satoh, et al. (2007). However, the presence of north-south-oriented low-velocity sedimentary formation around a $300 \mathrm{~m}$ depth interval along the foothills as observed by Dutta, Satoh, et al. (2007) has also been confirmed by the present analysis.

\section{Conclusions}

The available site response data $[\operatorname{SR}(f)]$ as a function of frequency have been inverted, in terms of layer thickness, shear-wave velocity, density, and shear-wave quality factor, by a simulated annealing method. The $\operatorname{SR}(f)$ observed for the Anchorage basin could be explained with reasonable certainty with the 1D structure of the subsurface sediments obtained for the aforesaid parameters. The spatial variation of the important parameter $\beta$ obtained from the results of 1D structures was then correlated with the available geological information. The results show that the Quaternary formations of the basin consist of fine-grain sediments; namely the BCF, glaciofluvial deposits, and recent sediments have $\beta$ values in the range of $180-500 \mathrm{~m} / \mathrm{sec}$. These formations overlie another Quaternary formation consisting of the coarse-grain sediments known as glacial till deposits with relatively higher $\beta(600-900 \mathrm{~m} / \mathrm{sec})$. The thickness of the fine-grain sediments is variable across the basin. It is less than $30 \mathrm{~m}$ thick in the eastern parts of the basin and attains a maximum depth of 55-60 m towards the western side before thinning out $(\sim 20 \mathrm{~m})$ towards the Knik Arm. The glacial till shows high levels of heterogeneity marked by variation of $\beta$ from 600 to $900 \mathrm{~m} / \mathrm{sec}$. Tertiary sediment with $\beta>$ $1000 \mathrm{~m} / \mathrm{sec}$ lies below the glacial till deposit at a depth of $200-250 \mathrm{~m}$ in the western part and increases to $150 \mathrm{~m}$ and around $100 \mathrm{~m}$ in the central and south central parts of the basin.

The prior study (Martirosyan et al., 2003) of site response modeling $(0.5-11.0 \mathrm{~Hz})$ in terms of shallow subsurface $\beta$ structure $(\sim 50 \mathrm{~m})$ at some selected sites in the Anchorage basin showed poor correlation between the observed and computed $\operatorname{SR}(f)$. Although the range of $\beta$ values of the shallow sediments obtained from the present and those proposed by Martirosyan et al. (2003) are nearly the same, the inclusion of deeper sedimentary structure $(\sim 400 \mathrm{~m})$ for site response modeling helps to explain the observed $\operatorname{SR}(f)$ much better than the previous one. Therefore, it can be concluded that the observed $\operatorname{SR}(f)$ for the Anchorage basin in the $0.5-11.0 \mathrm{~Hz}$ frequency band represent the overall effects of relative variation of sediments up to a depth of $400 \mathrm{~m}$ belonging to three major geological units previously mentioned. Thus, the interpretation of strong ground motions based on the uppermost $30 \mathrm{~m}$ of geological formations in the Anchorage basin are likely to yield erroneous results.

\section{Data and Resources}

All data used in this article are taken from published sources listed in the references. The Generic Mapping Tool (Wessel and Smith, 1998) was used to plot Figures 1 and 8.

\section{Acknowledgments}

We are grateful to A. Martirosyan of the Geophysical Institute (GI), University of Alaska, Fairbanks, for a review of this article. The research was supported in part by the GI, the Environment and Natural Resources Institute, and the School of Engineering of the University of Alaska, Anchorage. We are also thankful to R. Castro and another anonymous reviewer for their critical reviews and comments that helped improve the manuscript. U. D. is particularly thankful to the Institute for Geophysics, University of Texas at Austin, for allowing him to use their computational facilities.

\section{References}

Anderson, J. G., Y. H. Lee, Y. H. Zeng, and S. Day (1996). Control of strong motion by the upper 30 meters, Bull. Seismol. Soc. Am. 86, $1749-1759$.

Badal, J., U. Dutta, F. J. Seron, and N. Biswas (2004). 3D imaging of shear wave in uppermost $30 \mathrm{~m}$ soil column in Anchorage, Alaska, Geophys. J. Int. 158, 983-997.

Bard, P. Y., and J. Riepl-Thomas (2000). Wave propagation in complex geological structures and their effects on the strong ground motions, in Wave Motion in Earthquake Engineering, E. Kausel and G. Manolis (Editors), WIT Press, Southampton, 37-95.

Combellick, R. (1999). Simplified geological map of central and east Anchorage, Alaska, scale 1:25,000, Alaska Div. Geol. Geophys. Surv., Fairbanks, Alaska.

Dowl Engineers (1985). Ground Response Analysis: West Northern Lights Bridge, report, Anchorage, Alaska, 24 pp.

Dutta, U., M. K. Sen, N. Biswas, and Z. Yang (2007). Waveform inversion using local earthquake data for 1-D ground motion modeling at the Delaney Park downhole array site in Anchorage, Alaska, Seism. Res. Lett. 78, 279.

Dutta, U., N. Biswas, D. Adams, A. Martirosyan, and A. Papageorgiou (2004). Analysis of $S$-wave attenuation in south central Alaska, Bull. Seismol. Soc. Am. 94, 16-28.

Dutta, U., N. Biswas, A. Martirosyan, A. Papageorgiou, and S. Kinoshita (2003). Estimation of earthquake source parameters and site response in Anchorage, Alaska from strong motion network data using generalized inversion method, Phys. Earth Planet. Interiors 137, 13-29.

Dutta, U., A. Martirosyan, N. Biswas, A. Papageorgiou, M. Dravinski, and R. Combellick (2001). Estimation of $S$-wave site response in Anchorage, Alaska, from weak motion data using generalized inversion method, Bull. Seismol. Soc. Am. 91, 335-346.

Dutta, U., N. Biswas, A. Martirosyan, S. Nath, M. Dravinski, A. Papageorgiou, and R. Combellick (2000). Delineation of spatial variation of shear wave velocity with high frequency Rayleigh waves in Anchorage, Alaska, Geophys. J. Int. 143, 365-375.

Dutta, U., T. Satoh, H. Kawase, T. Sato, N. Biswas, A. Martirosyan, and M. Dravinski (2007). $S$-wave velocity structure of sediments in Anchorage, Alaska estimated with array measurements of microtremors, Bull. Seismol. Soc. Am. 97, 234-255.

Hartzell, S., D. Carver, R. A. Williams, S. Harmsen, and A. Zerva (2003). Site response, shallow shear-wave velocity, and wave propagation at the San Jose, California, dense seismic array, Bull. Seismol. Soc. Am. 93, 443-464.

Ingber, L. (1989). Very fast simulated reannealing, Math. Comput, Model. 12, 967-993.

Kirkpatrick, S. G., C. D. Delatt Jr., and M. P. Vecchi (1983). Optimization by simulated annealing, Science 220, 671-680. 
Kramer, S. (1996). Geotechnical Earthquake Engineering, Prentice Hall, New York.

Martirosyan, A., N. Biswas, U. Dutta, D. Cole, and A. Papageorgiou (2003). Ground motion analysis in the Anchorage basin: 1-D approach, $J$. Earthq. Eng. 7, 251-274.

Martirosyan, A., U. Dutta, N. Biswas, A. Papageorgiou, and R. Combellick (2002). Determination of site response in Anchorage, Alaska on the basis of spectral ratio methods, Earthq. Spectra 18, 85-104.

Meteropolis, N., A. Rosenbluth, M. Rosenbluth, and A. Teller (1953). Equation of state calculations by fast computing machines, J. Chem. Phys. 21, 1087-1092.

Nath, S. K., D. Chatterjee, N. N. Biswas, M. Dravinski, D. A. Cole, A. Papageorgiou, J. A. Rodriguez, and C. J. Poran (1997). Correlation study of shear wave velocity in near surface geological formations in Anchorage, Alaska, Earthq. Spectra 13, 55-75.

Schmoll, H. R., and E. Dobrovolny (1972). Generalized geologic map of Anchorage and vicinity, Alaska, U.S. Geol. Surv. Misc. Geol. Invest. Map I-787-D, scale 1:24,000.

Sen, M. K., and P. L. Stoffa (1991). Non-linear one-dimensional seismic waveform inversion using simulated annealing, Geophysics 56, $1624-1638$

Sen, M. K., and P. L. Stoffa (1995). Global Optimization Methods in Geophysical Inversion, Elsevier, Amsterdam.

Sen, M. K., and P. L. Stoffa (1996). Bayesian inference, Gibbs sampler and uncertainty estimation in geophysical inversion, Geophys. Prosp. 44, 313-350.

Tarantola, A. (1987). Inverse Problem Theory, Methods of Data Fitting and Model Parameter Estimation, Elsevier, Amsterdam.

Updike, R. G., and C. A. Ulery (1986). Engineering geologic map of southwest Anchorage, Alaska, Alaska Div. Geol. Geophys. Surv. Report No. 89, Fairbanks, Alaska.

Wessel, P., and W. H. F. Smith (1998). New, improved version of Generic Mapping Tool released, Eos Trans. AGU 79, 579.
Wesson, R., A. Frankel, C. Mueller, and S. Harmsen (1999). Probabilistic seismic hazard maps of Alaska, U.S. Geol. Surv. Open-File Rept. 99-36.

Woodward-Clyde Consultants (1987). Geotechnical Investigation: Anchorage Courthouse Addition, technical report, Vol. I and II, Anchorage, Alaska.

Yehle, L. A., J. K. Odom, H. R. Schmoll, and L. L. Dearborn (1986). Overview of the geology and geophysics of the Tikishla Park drillhole, USGS A-84-1, Anchorage, Alaska, U.S. Geol. Surv. Open-File Rept. 86-293.

Department of Civil Engineering

University of Alaska, Anchorage

3211 Providence Drive

Anchorage, Alaska 99508

(U.D., Z.Y.)

Jackson School of Geosciences

University of Texas at Austin

10100 Burnet Road

Building 196

Austin, Texas 78758

(M.K.S.)

Geophysical Institute

University of Alaska, Fairbanks

P.O. Box 757320

Fairbanks, Alaska 99775-7320

(N.B.)

Manuscript received 10 October 2007 